\title{
Trabajo, familia y cambios en la política pública en América Latina: equidad, maternalismo y corresponsabilidad
}

\author{
Merike Blofield y Juliana Martinez F.
}

RESUMEN

Teniendo como telón de fondo el aumento sustantivo de la participación laboral femenina en toda la región latinoamericana, en este artículo se caracterizan las políticas adoptadas para conciliar la vida familiar y laboral entre 2003 y 2013, así como las implicaciones del diseño de estas medidas para la equidad socioeconómica y de género. Se abordan los casos de la Argentina, el Brasil, Chile, Costa Rica y el Uruguay, cinco países de la región que, en función de sus trayectorias históricas, tienen las mejores condiciones relativas para ejecutar medidas que reorganicen tiempos, ingresos y servicios. El análisis empírico indica, primero, que estas transformaciones favorecieron más homogéneamente la equidad socioeconómica que la equidad de género. Segundo, se identificaron variaciones significativas entre países, tanto en la magnitud como en el tipo de cambio ocurrido. El trabajo concluye con interrogantes sustantivos respecto de las medidas, su implementación y efectividad, y las variaciones entre países.

PALABRAS CLAVE

CLASIFICACIÓN JEL

AUTORAS
Mujeres, empleo de la mujer, familia, roles de los géneros, igualdad de género, derechos de la mujer, política social, Argentina, Brasil, Chile, Costa Rica, Uruguay

$\mathrm{I} 38$
Merike Blofield es profesora asociada de la Universidad de Miami. m.blofield@miami.edu

Juliana Martínez F. es profesora asociada de la Universidad de Costa Rica. juliana.martinez@ucr.ac.cr 


\section{I}

\section{Introducción}

América Latina experimenta una "revolución silenciosa" (Goldin, 2006) en la intersección entre trabajo y familia. Siete de cada 10 mujeres en edad reproductiva forman parte de la fuerza laboral y crecientemente habitan en hogares liderados por mujeres, muchos de estos monoparentales. Simultáneamente, los cuidados continúan siendo una responsabilidad sobre todo femenina (OIT/ PNUD, 2009; Sojo 2011; Montaño, 2010; CEPAL, 2013a). Las tensiones en las relaciones de género resultantes de esta combinación entre transformaciones y continuidades laborales y familiares tienen como telón de fondo una profunda desigualdad socioeconómica (Cornia, 2010; CEPAL, 2011; López-Calva y Lustig, 2010). ¿En qué medida los gobiernos han abordado estas tensiones y con qué implicaciones para la desigualdad? En este artículo se explora este interrogante a partir de las políticas adoptadas durante los 10 años de expansión económica, que tuvieron lugar a partir de 2003 en los cinco países que - como se discute posteriormente- cuentan con trayectorias históricas de mayor desarrollo relativo de política social en la región: Argentina, Brasil, Chile, Costa Rica y Uruguay.

Antes cabe explicitar cuál es la relevancia social y política de abordar las tensiones entre vida familiar y laboral. Primero, para las mujeres la responsabilidad en los cuidados constituye una fuerte barrera de acceso al mercado laboral (CEPAL, 2010). En una región tan desigual, esta brecha de género está marcadamente influenciada por la estratificación socioeconómica. La brecha de participación laboral femenina entre los quintiles de mayor y menor ingreso es, en promedio, del 30\% y no se ha reducido desde 1990, a pesar del notorio aumento en la participación laboral global de las mujeres ${ }^{1}$. Dado que la probabilidad de superar la condición de la pobreza es proporcional a la presencia

$\square$ Las autoras agradecen a Ariel Armony, Eleanor Faur, Janet Gornick, Evelyne Huber, Beatriz Magaloni, Esther Mancebo, Carmen Midaglia, Jennifer Pribble, Soledad Salvador, Silke Staab, Juan Diego Trejos, y a dos evaluadores anónimos de la Revista CEPAL. Agradecemos también a María Cristina Alcántara, Felipe Sterquino Itaborai y, especialmente, a Diana León por su rigurosa y entusiasta asistencia de investigación. Cualquier error de apreciación es de responsabilidad de las autoras.

${ }^{1}$ Por ejemplo, en el Brasil, la brecha es casi del $40 \%$, en tanto que solo el $46,5 \%$ de las mujeres de menores ingresos forman parte de la fuerza laboral, en comparación con el 84,4\% de las mujeres de los quintiles de mayores ingresos (PNAD/IBGE, 2014; Sorj y Fontes, 2012). de más de un ingreso en las familias (OIT/PNUD, 2009), la no participación laboral femenina agrava la pobreza y la desigualdad social. Segundo, las mujeres con ingresos propios están sobrerrepresentadas en el autoempleo y el trabajo doméstico, ocupación en la que en 2008 tres cuartos de las personas, casi todas ellas mujeres, carecían de un plan de pensión (OIT, 2011). La inserción laboral femenina tiene, por lo tanto, una menor protección laboral que la de sus pares varones —en áreas urbanas cuentan con seguridad social solo el $36 \%$ de las mujeres en comparación con el $49 \%$ de los hombres (OIT/PNUD, 2009)—. Tercero, la desprotección social aumenta entre quienes tienen mayores demandas de apoyo en los cuidados: en 12 países de América Latina, las mujeres con educación primaria incompleta tienen entre 2 y 3,5 más hijos/as que las que cuentan al menos con educación secundaria (CEPAL, 2011, pág. 85). En los hogares monoparentales encabezados por mujeres, la doble tarea de proveer cuidados e ingresos de manera exclusiva exacerba las consecuencias negativas de la informalidad laboral y la desprotección social.

La actual situación representa tanto un reto como una oportunidad (OIT/PNUD, 2009; Sojo, 2011; Montaño Virreira, 2010; Chioda, 2011). Mediante políticas públicas adecuadas, los gobiernos podrían interrumpir el actual círculo de reproducción de la desigualdad, así como promover un desarrollo social y económico más inclusivo. Varias de las medidas pueden lograr más de un objetivo a la vez. Por ejemplo, existe consenso en que los servicios de cuidado y la educación prescolar desarrollan capital humano e igualan oportunidades. Con horarios y jornadas adecuadas, estos servicios pueden simultáneamente apoyar a madres y padres trabajadores. Por el contrario, de no mediar respuestas adecuadas a las tensiones entre vida familiar y laboral, pueden profundizarse las desigualdades socioeconómicas y de género, con consecuencias dañinas para la equidad y el desarrollo de la región.

¿Cuánto se ha avanzado en materia de adopción de políticas públicas relevantes para la conciliación entre vida familiar y laboral en aquellos países con mejores condiciones relativas para hacerlo? A continuación, en la sección II se presenta el marco analítico mediante el cual se abordan estos cambios. En la sección III se explica la metodología, y luego, en la sección IV, se muestran los hallazgos empíricos. Se concluye con una síntesis y discusión de dichos hallazgos en la sección V. 


\section{II}

\section{Marco analítico ${ }^{2}$}

El universo de políticas públicas que, por acción u omisión, intervienen en la relación entre vida familiar y laboral es amplio e incluye desde medidas de planificación urbana y de transporte público, hasta medidas propiamente sociales relacionadas con las licencias y los cuidados (Monge, 2006). A continuación, se distingue entre distintos tipos de política social que afectan a la relación trabajo-familia, para luego discutir cómo estos mantienen o transforman las relaciones socioeconómicas y de género $^{3}$. La sección concluye con la presentación de ejemplos de políticas específicas con cuyo diseño se procura alterar la desigualdad socioeconómica y de género inicial.

\section{Políticas que reconcilian vida familiar y laboral}

Existen tres tipos de intervención que permiten conciliar vida familiar y laboral en tanto reasignan tiempo, ingresos y servicios, respectivamente, ya sea de manera positiva o negativa para la igualdad socioeconómica y de género. Lo que estas medidas permiten concretamente es alternar tiempos laborales y tiempos destinados a los cuidados dentro de la familia (Durán, 2004), transferir los cuidados de las familias a servicios con alguna participación del Estado, y regular la contratación privada de servicios de cuidados por parte de las familias. Esta intervención del Estado es de índole secuencial, "desfamiliarista" (Martínez Franzoni, 2008; Orloff, 2009) y regulatoria, respectivamente ${ }^{4}$, y se expresa en medidas no siempre concebidas desde un principio para abordar las tensiones entre responsabilidades laborales y familiares, como es el caso de los servicios para la niñez en edad preescolar. Además, como se ilustra a continuación, cada uno de estos tres tipos de medidas puede abordarse tanto desde la política laboral como desde la política social.

\footnotetext{
${ }^{2}$ Este marco analítico ha sido desarrollado de manera más detallada en Blofield y Martínez Franzoni (2014).

${ }^{3}$ En este artículo se hace referencia a esta tensión de manera indistinta como trabajo-familia, vida familiar y laboral, y responsabilidades familiares y laborales.

4 Al considerar los tres tipos de medidas, aunque definiendo de manera distinta las medidas de índole regulatoria, Martínez Franzoni y Camacho (2006 y 2007) elaboraron un primer intento exploratorio de los cambios ocurridos en América Latina a partir de una adaptación de Durán (2004).
}

- Las políticas secuenciales se refieren a medidas que protegen la seguridad de los ingresos durante los tiempos - mensuales, semanales o diariosdestinados a los cuidados. Incluyen las licencias por maternidad, por paternidad y parentales, pero también políticas de flexibilidad horaria y de trabajo de tiempo parcial. La secuenciación puede durar meses e involucrar muchos días de trabajo (como lo es en la licencia de maternidad) o durar horas dentro de una misma jornada semana laboral (como en el caso del trabajo de tiempo parcial o de cierto tipo de jornadas flexibles, respectivamente). Con las políticas secuenciales, el cuidado permanece en las familias, históricamente en las mujeres, aunque más tarde y de manera creciente estas medidas se han ido ampliando a los hombres con responsabilidades familiares a través de licencias parentales y paternales ${ }^{5}$.

- Las políticas de desfamiliarización de los cuidados se refieren a transferencias y servicios que delegan responsabilidades de cuidado desde las familias $-\mathrm{y}$ concretamente desde las mujeres - a servicios con alguna intervención estatal. Estos pueden brindarse de forma directamente pública, conllevar incentivos o subsidios para la prestación privada, o bien legislar la prestación obligatoria de subsidios, servicios o de ambos por parte de empleadores y empleadoras. $\mathrm{Al}$ igual que las políticas secuenciales, estas medidas giran por lo general en torno a las madres y mujeres trabajadoras, pero - como se elabora con mayor detalle más adelante en este mismo artículo- en América Latina han comenzado gradualmente a hacer elegibles también a los padres (OIT/PNUD, 2009).

- La tercera categoría corresponde a las regulaciones con respecto a la contratación de cuidados provistos de manera remunerada desde el hogar que, precisamente por ello, transforman el domicilio

\footnotetext{
5 Las licencias parentales se crearon inicialmente en Europa, concretamente en Suecia, en 1974. Las licencias por paternidad son posteriores y fueron pensadas para promover que los hombres efectivamente tomaran una parte de las licencias parentales. Tanto las licencias por maternidad como las parentales y paternales son considerablemente más extensas en Europa y los países anglófonos, con la excepción de los Estados Unidos de América, que se encuentran rezagados incluso respecto de los países rezagados de América Latina.
} 
en lugar de trabajo. Se tratan estas de "políticas regulatorias de la compra de servicios que se brindan desde el domicilio de quien lo contrata". La contratación individual de personal mayoritariamente femenino para trabajos en el ámbito doméstico es una alternativa al servicio prestado desde instituciones dedicadas a los cuidados, con implicaciones distintas para el papel que el Estado asume en materia de cuidados de "desfamiliarización" y de mercantilización, respectivamente, puesto que generalmente la regulación del trabajo doméstico remunerado no está incluida bajo el concepto de políticas de conciliación entre trabajo y responsabilidades familiares.

El principal interés en este estudio radica en el trabajo doméstico considerado como no calificado ${ }^{6}$, a pesar de que el análisis puede extenderse a ocupaciones calificadas, como la enfermería. Al igual que en otras ocupaciones relacionadas con los cuidados, el trabajo domiciliario suele ser abrumadoramente femenino y por ello castigado con remuneraciones menores respecto de actividades laborales con similar calificación. Ello deriva de tres factores: se trata de tareas históricamente concebidas como extensiones de papeles femeninos "naturales"; son percibidas como intrínsecamente satisfactorias para quienes las llevan a cabo; y, en tanto “actividades sagradas", son ubicadas más allá del reconocimiento monetario (England y Folbre, 1999).

La provisión de los cuidados (remunerados o no) involucra una conexión emocional entre quienes los proveen y quienes los reciben; asimismo, la regulación laboral es crítica tanto para las cuidadoras en su condición de trabajadoras, como para el tipo y la calidad del servicio brindado (véanse, por ejemplo: Folbre, $1995^{7}$ y Williams, 2010). Una característica distintiva del trabajo de cuidado es que el espacio laboral y el domicilio de las personas que se cuida se superponen, y que los lazos entre quienes dan y quienes reciben los cuidados tienden a ser más personales. Esta característica torna más compleja la regulación de estas ocupaciones en general, y de la que se realiza en los hogares de los empleadores, en

\footnotetext{
${ }^{6}$ Por trabajo doméstico no calificado se entiende aquel que atañe a personas que rara vez tienen una capacitación formal para el desempeño ocupacional, incluso cuando los servicios que proveen requieren de un amplio conjunto de capacidades prácticas que son socialmente poco valoradas.

${ }^{7}$ Folbre (1995) define el trabajo de cuidado, sea o no remunerado, como aquel que involucra una conexión con las personas a quienes se debe atender. La autora argumenta la motivación intrínseca que conlleva este tipo de trabajo en tanto actividad dirigida a terceros, y que crea desafíos específicos a su organización y remuneración en el mercado.
}

particular. Históricamente arraigada en una cultura de servidumbre, la discriminación ha sido establecida en leyes y códigos del trabajo, con largas jornadas laborales y protecciones y beneficios laborales muy limitados.

En América Latina, el trabajo doméstico o domiciliario es precisamente una de las maneras predominantes de resolución de las tensiones entre vida familiar y laboral: en él se emplean alrededor del 15\% de las mujeres trabajadoras económicamente activas e involucra a un porcentaje similar de personas adultas que cuentan con trabajo doméstico remunerado en sus hogares (CEPAL, 2013b; OIT 2012, págs. 59 y 60). La débil regulación estatal de esta ocupación ha conllevado que, en los hechos, la conciliación entre responsabilidades laborales y familiares de las familias de mayores ingresos tenga lugar a expensas de la conciliación entre vida familiar y laboral por parte de estas mismas mujeres trabajadoras (Blofield, 2012).

Otra forma colectiva del trabajo de cuidado en el hogar (también referida como trabajo de cuidado familiar) es aquel que se lleva a cabo en el hogar de quien cuida. Aunque estos arreglos sin duda han existido de manera informal a lo largo del tiempo, durante las últimas décadas se han convertido en objeto de regulación gubernamental y destino de fondos públicos en el marco de la ampliación de servicios sociales hacia las familias de menores ingresos.

Con respecto a los tres tipos de política pública, se encuentran intervenciones tanto en materia de política laboral como social. También en los tres casos el Estado puede intervenir tanto por acción como por omisión, dejando las soluciones a la tensión entre vida familiar y laboral en manos de estrategias familiares y femeninas informales, en la forma de trabajo no remunerado, voluntario o mal remunerado, o promoviendo la prestación de servicios mediante profesionales capacitados(as) contratados(as) bajo condiciones formales.

Las políticas secuenciales, desfamiliaristas y regulatorias son cualitativamente distintas y complementarias de la conciliación trabajo-familia. Por ello, es esperable que una mayor presencia de uno de estos tipos de políticas no compense de manera adecuada la ausencia de los otros. Por ello, en el análisis empírico debe tenérseles presente simultáneamente.

\section{Consecuencias para la equidad socioeconómica y de género}

Al reasignar tiempos, protección de ingresos y servicios en su propio diseño y más allá de su implementación, las medidas secuenciales, desfamiliaristas y regulatorias 
pueden reforzar o alterar la desigualdad socioeconómica - tal como resulta de la distribución primaria del ingreso, producto sobre todo del mercado laboral- y de género, como la construye la división sexual del trabajo entre mujeres y hombres. Nótese que lejos de evaluar cómo las medidas vigentes transforman la estructura social — si es que efectivamente lo hacen-, en este trabajo el análisis se enfoca en el diseño de estas medidas.

Comencemos por la desigualdad de género. En la literatura sobre estados de bienestar y relaciones de género se distingue entre políticas "maternalistas" y aquellas que promueven "corresponsabilidad social" en materia de cuidados (OIT/PNUD, 2009). Con las medidas maternalistas (Orloff, 2006) se reconoce la importancia de los cuidados y se exalta "la capacidad de las mujeres para ser madres" (Koven y Michel, 1993, en Orloff, 2006, pág. 4). Por eso, con estas medidas se procura premiar a las mujeres en tanto primeras y principales responsables de proveer los cuidados ${ }^{8}$, y lograr el reconocimiento social de los cuidados antes que reducir la brecha de género existente en su desempeño. Licencias maternales extensas, incentivos fiscales o transferencias monetarias para que las madres se queden en la casa son ejemplos de medidas maternalistas. Estas últimas se plantean como alternativas a la mayor participación de los padres, a la utilización de servicios o a ambas.

Distinguiéndolo de medidas maternalistas, se identifica un "piso maternalista" que reconoce el papel específico de las mujeres en la gestación, el dar a luz, en amamantar y en establecer rutinas y vínculos iniciales. Se trata de categorías analíticas, pero también de umbrales históricamente cambiantes. Por ejemplo, la demarcación de lo que se considera un mínimo de licencia por maternidad por parte de la oIT $-\mathrm{y}$ al que aquí se recurre para definir lo que se denomina el piso maternalista — ha ido cambiando a lo largo del tiempo. En 1952, la Organización Internacional del Trabajo (OIT) entendía que las licencias maternales debían durar 12 semanas (Convenio 103), pero para el año 2000 el mínimo se establecía en 14 semanas (Convenio 183).

Un piso maternalista es esencial para proteger a las mujeres en su condición de madres. Sin embargo, las

\footnotetext{
${ }^{8}$ Históricamente, los movimientos maternalistas trabajaron en favor de la justicia de género desde un feminismo de la diferencia: "Las mujeres podrían ser reconocidas y compensadas por el Estado por sus contribuciones particulares a la sociedad a través de la maternidad y la crianza de los(as) hijos(as)" (Orloff, 2006, pág. 10; traducción propia). Los argumentos maternalistas pueden perder terreno ante una visión de los cuidados que involucra pero trasciende a las mujeres. Orloff (2006) argumenta que en los Estados Unidos de América ha venido teniendo lugar un menor apoyo popular y de las élites al maternalismo, sin que ello conlleve necesariamente una mayor equidad socioeconómica.
}

políticas maternalistas pueden afectar a la equidad de maneras contradictorias. Si bien dichas políticas reconocen públicamente y apoyan la maternidad como dimensión central en la vida de las mujeres, elevando entonces el estatus maternal, refuerzan a la vez la noción de que el cuidado es únicamente responsabilidad femenina. Es materia empírica establecer cuáles políticas maternalistas promueven también la equidad de género al "emparejar la cancha" en lugar de reforzar la división sexual del trabajo entre hombres y mujeres.

En contrapunto al maternalismo, la corresponsabilidad redistribuye responsabilidades de cuidados, tanto de las familias al Estado (corresponsabilidad estatal) como de las mujeres a los hombres (corresponsabilidad paterna).

La corresponsabilidad estatal en políticas que reconcilian trabajo y familia conlleva no solo la desfamiliarización mediante la prestación pública o los subsidios a la oferta privada de servicios de Atención y Educación de la Primera Infancia (AEPI $\left.{ }^{9}\right)$, sino también, y muy importante, jornadas de trabajo compatibles con la jornada laboral de tiempo completo, a objeto de permitir utilizar dichos servicios a madres y padres. La inversión pública social en servicios de educación en primera infancia que no correspondan a típicas horas laborales, apoya la corresponsabilidad estatal en materia educativa, pero no en cuanto a la conciliación entre trabajo y familia.

Con la corresponsabilidad paterna se procura balancear la presencia de los padres en los cuidados. De esta manera se alteran diferencias entre hombres y mujeres originadas en una especialización de tareas generadoras de ingresos y de cuidados, respectivamente (Fraser, 1997). Este propósito de "feminizar el ciclo de vida masculino" (Esping-Andersen, 2009, pág. 99) generalmente conlleva políticas secuenciales que permiten reorganizar roles de género entre madres y padres, sin que se vea amenazada la remuneración o la continuidad laboral.

Al asignar más responsabilidades de cuidado al Estado y a los padres, estas políticas tienen la capacidad de reducir las inequidades de género en la carga asistencial. La extensión a la que se llega en la práctica con tales políticas es materia empíric. La experiencia sueca con las licencias por paternidad no transferibles a las madres muestra que estas medidas son mejores para la participación paterna en el cuidado infantil que los permisos parentales, para los cuales los padres son tan elegibles como las

\footnotetext{
9 Aunque la traducción no es literal, esta definición es equivalente a lo que en inglés se denomina como Early Child Education and Care (ECEC).
} 
madres. Tanto los permisos para padres, consistentes en unos pocos días de acompañamiento a las madres, como los permisos parentales han sido establecidos de manera muy reciente en Chile y el Uruguay, por lo que el conocimiento de sus efectos en la reducción de las desigualdades de género en el trabajo de cuidados es aún muy incipiente.

En términos de equidad socioeconómica, en este trabajo se parte de los principales criterios que permiten el acceso a la política social: necesidad, contribución o ciudadanía (Esping-Andersen, 1990). Estos criterios tienen distintas implicaciones según se trate de escenarios de relativa igualdad socioeconómica, pocas personas en condiciones de pobreza y mercados laborales básicamente formales. O todo lo contrario, como en la región latinoamericana, donde el carácter altamente informal de sus mercados de trabajo limita los alcances del acceso contributivo e interpela a los mecanismos de acceso vinculados a la ciudadanía y a la necesidad en mayor medida que en los países desarrollados ${ }^{10}$.

$\mathrm{Al}$ detallar mejor este argumento, se observa en primer lugar que las políticas basadas en contribuciones relacionadas con el empleo formal generalmente restringen los beneficios a aquellas personas que contribuyen regularmente y a sus dependientes -incluso segmentando beneficios entre unos y otros- Este acceso está más presente entre los grupos de ingresos medios y medio-altos de la población, reforzando las inequidades socioeconómicas ${ }^{11}$. Dichas políticas tienden también a reforzar brechas entre grupos dentro de la fuerza laboral formal; por ejemplo, entre quienes cuentan con contratos de duración determinada o realizan trabajo doméstico remunerado, que pueden no tener legalmente acceso a los mismos derechos.

Puesto que un rasgo significativo de los mercados laborales latinoamericanos es su informalidad (expresada, por ejemplo, en el trabajo temporal y doméstico), interesa determinar si las medidas implementadas trascienden el trabajo asalariado formal y alcanzan a distintos tipos de asalariados, al trabajo independiente o a ambos ${ }^{12}$.

\footnotetext{
${ }^{10}$ Aun así, cabe tener presente que la protección social contributiva tiene mayor alcance relativo e inversión social que la mayoría de los programas de carácter no contributivo.

${ }^{11}$ Para una discusión de casos relevantes donde el universalismo ha sido construido sobre las políticas contributivas, véanse Martínez Franzoni y Sánchez-Ancochea (2013).

12 En América Latina, la protección laboral y social alcanza a los(as) trabajadores(as) en varios grados, dando lugar a una continuidad
}

También se evalúa si las políticas trascienden su estrecha relación con la ubicación laboral de las personas para plantearse en función de criterios de necesidad o de ciudadanía. De esta manera, se valora si las políticas conciliatorias — sean secuenciales, desfamiliaristas o regulatorias, maternalistas o procorresponsabilidadalteran o reproducen la estratificación inicial vinculada al mercado laboral y, por lo tanto, mejoran también la equidad socioeconómica ${ }^{13}$.

En segundo lugar, la informalidad impregna los arreglos en materia de cuidados, ya sea a través de la contratación informal de las trabajadoras domésticas o del trabajo femenino no remunerado. Sin la intervención de los gobiernos, los cuidados recaen marcadamente en las mujeres de menores ingresos. Dicho de otro modo, los grados de familiarización de los cuidados (Martínez Franzoni, 2008; Orloff, 2009) difieren entre estratos socioeconómicos. Cuanto mayor es el ingreso de las familias, mayor es su capacidad de trasladar buena parte de los quehaceres domésticos a las mujeres de menores ingresos contratadas para tal fin, evitando así tener que negociar una reorganización de las responsabilidades de cuidado con sus pares varones. Por el contrario, cuanto menor es el ingreso, menores son también las opciones de delegar el trabajo doméstico y de cuidados de manera remunerada.

Dadas las interacciones entre desigualdades socioeconómicas y de género, se debe evitar subsumir una en la otra y más bien examinar sus interacciones a través de distintas iniciativas de las políticas. Los tres tipos de política — secuencial, desfamiliarista y regulatoria- pueden tener implicaciones diversas para las relaciones socioeconómicas y de género. En términos empíricos, en materia de equidad de género se procura establecer si las medidas promueven un piso de maternidad, maternalismo o corresponsabilidad. En cuanto a la desigualdad socioeconómica, se determina si la protección se extiende más allá del trabajo asalariado y los mecanismos contributivos para alcanzar el autoempleo y el trabajo temporal, también sobre la base de la necesidad o de la ciudadanía.

que va desde lo más formal a los acuerdos más informales entre trabajadores(as) asalariados(as) como también independientes. En vez de dar forma a un "sector" informal, la informalidad constituye un rasgo que atraviesa el mercado laboral.

13 Véase Pribble (2013) para una discusión amplia de políticas sociales que promueven la equidad. 


\section{III}

\section{Metodología}

A continuación, se analizan las licencias remuneradas por nacimiento, los servicios de cuidado infantil de tiempo completo y la equiparación de derechos de las trabajadoras domésticas remuneradas, en tanto políticas que si bien no agotan el universo de medidas secuenciales, desfamiliarizadoras y regulatorias, sí son emblemáticas de políticas secuenciales, desfamilialistas y regulatorias, respectivamente.

Los casos nacionales considerados corresponden a los cinco países latinoamericanos con mejores condiciones relativas para responder a las transformaciones de las familias y los mercados laborales de la región: Argentina, Brasil, Chile, Costa Rica y Uruguay. Corresponden al grupo de países con brechas sociales modestas (Filgueira, 2011) y que cuentan con mercados laborales comparativamente más formales y una mayor inversión social relativa. Debido a estas características, se los considera generalmente como parte de un mismo régimen de política social, de carácter estatal (Martínez Franzoni, 2008) o avanzado (Huber y Stephens, 2012). Tienen sistemas políticos altamente institucionalizados y una mayor capacidad estatal (Pribble, 2013), y experimentan transiciones demográficas más avanzadas (CEPAL, 2010).

Respecto de las medidas y los países mencionados se comparan las políticas vigentes a nivel federal en 2003 y 2013. Conviene estar conscientes de la amplia brecha que puede tener lugar entre las medidas formalmente vigentes y su implementación. Sin embargo, la adopción de medidas es en sí misma indicativa de las prioridades de política existentes. Además, su comprensión es condición necesaria para hacer valorizaciones más integrales que incluyan el análisis de la implementación de los cambios en cuestión. Se dejan de lado medidas legislativas y ejecutivas debatidas, pero aún no adoptadas, así como convenios colectivos (sobre todo importantes en el Uruguay, el Brasil y la Argentina) y legislación estatal particularmente prominente en los dos países federales analizados (Argentina y Brasil), pero que trasciende los mínimos comunes a nivel nacional.

La evidencia empírica utilizada proviene de fuentes primarias y secundarias. Entre las primeras se encuentran leyes, decretos ejecutivos y documentos de política, reportes de comisiones ejecutivas o de los congresos y entrevistas, como también artículos de periódicos. Entre las fuentes secundarias se encuentran los análisis de países, varios de los cuales presentan un abordaje de índole sociológica o tienen una intención evaluativa o de brindar insumos de política ${ }^{14}$.

\footnotetext{
14 Respecto de los cinco países existe una interesante y creciente literatura sobre el tema. A modo de ejemplo, para la Argentina, véanse Faur (2011); Faur, Esquivel y Jelin (2012); Gherardi, Pautassi y Zibecchi (2012) y Rodríguez y Pautassi (2014); para el Brasil, véanse Hirata y Araujo Guimarães (2012), y Sorj (2013); para Chile, véanse Bentancor y De Martini (2012), y Staab (2012) (este último con un foco explícito en formacion de políticas); para Costa Rica, véanse Román y Morales (2010); y Sauma (2012); para el Uruguay, véanse Aguirre y Ferrari (2014) —enfocado estrictamente en el proceso de adopción de políticas-; Batthyany, Genta y Perrotta (2012), y Salvador (2013).
}

\section{La evidencia empírica: políticas conciliatorias en 2003 y 2013}

A continuación se desagrega la evidencia empírica relevada respecto de las licencias remuneradas por nacimiento, los servicios de cuidados destinados a la primera infancia y los derechos del trabajo doméstico remunerado en tanto casos de políticas conciliatorias secuenciales, desfamiliarizadoras y regulatorias, respectivamente. Los hallazgos muestran que durante este período han ocurrido más cambios en materia de servicios de cuidado y de regulación del trabajo doméstico que de las licencias vinculadas al trabajo remunerado.

Con respecto a esto último, las reformas legales de mayor alcance han tenido lugar en Chile y el 
Uruguay, tanto en términos de su duración como de los criterios de acceso. En los otros tres países, grupos de mujeres trabajadoras han obtenido acceso a permisos de maternidad, ya sea mediante resoluciones judiciales (Brasil y Costa Rica) o reformas legislativas (Argentina).

Los servicios de cuidado han experimentado transformaciones, aunque variables, en todos los países. En general, en materia de adopción de medidas, los avances en aquellas que promueven la equidad socioeconómica son mayores que en las medidas atinentes a la corresponsabilidad paterna.

\section{Medidas secuenciales: mayor maternalismo y equidad socioeconómica}

¿En qué medida ha habido cambios en materia de licencias vinculadas al trabajo remunerado y de qué tipo? En el gráfico 1 se denota la duración en semanas de las licencias remuneradas maternales, paternales y parentales en los cinco países en 2003 y 2013. Las licencias analizadas tienen en común que equivalen al salario completo - aunque pueden tener un tope como en Chile-, pero se diferencian en cuanto a la fuente de financiamiento (procedentes de la seguridad social en la Argentina, el Brasil y el Uruguay; de una combinación entre la seguridad social y los empleadores en Costa Rica; y del presupuesto nacional en Chile). El mejor escenario para la equidad socioeconómica y de género es aquel en que las licencias no representen un costo directo para los empleadores ${ }^{15}$.

Las licencias de maternidad remuneradas fueron institucionalizadas con la consolidación de códigos laborales en décadas anteriores, y en 2003 tenían un rango entre 12 semanas en el Uruguay y unas 18 semanas en Chile. En 2003, las licencias de paternidad tenían un rango de 0 días (Costa Rica y Uruguay), de 1 día (Chile), de 2 días (Argentina) y de 5 días en el Brasil (consagrados en la Constitución de 1988). Con excepción de la Argentina, el período durante el cual las madres disfrutan de las licencias maternales cuenta también para acceder a las pensiones por vejez.

El gráfico 1 permite distinguir entre medidas que corresponden al piso maternalista (equivalente al mínimo de 14 semanas definido por la OIT, identificado con una línea), medidas maternalistas (por sobre dicho piso), y medidas que promueven la corresponsabilidad tanto mediante licencias exclusivas para padres (licencias por paternidad), como por medio de licencias compartibles entre madres y padres (licencias parentales).

\footnotetext{
15 Cuando las licencias sí representan un costo directo para quienes emplean, además de desincentivar la contratación de mujeres, ello afecta más a las empresas cuanto más pequeñas son, resultando por lo tanto regresivo para la estructura productiva. Para encontrar datos y análisis acerca de la región en su conjunto, véase Pautassi y Rico (2011).
} GRÁFICO 1

Licencias por nacimiento y equidad de género por país, 2003 y 2013 (En semanas)

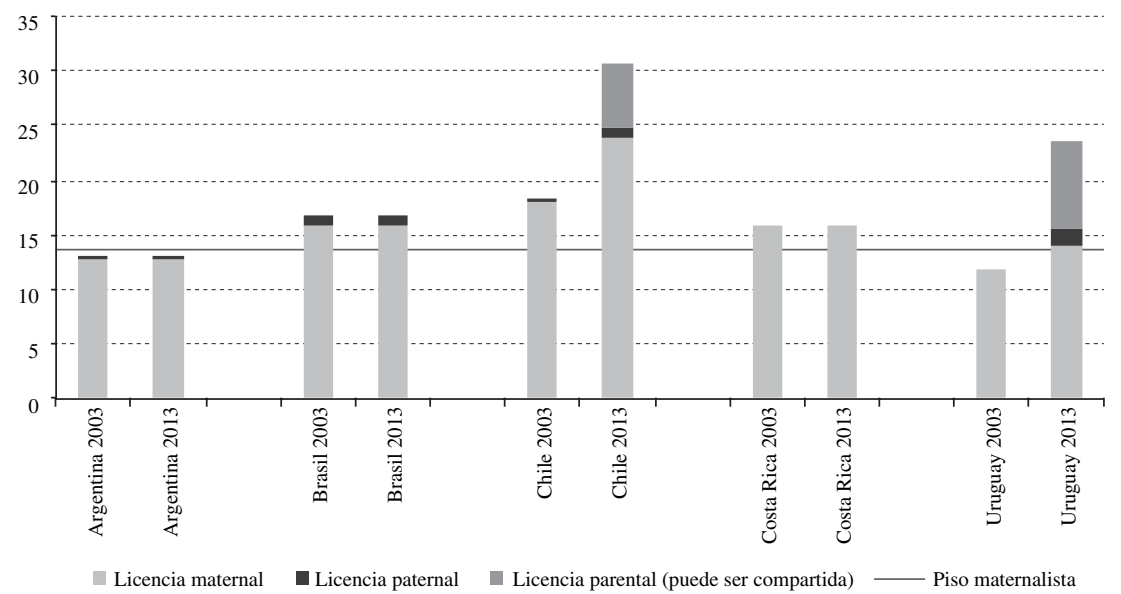

Fuente: elaboración propia sobre la base de las leyes de los respectivos países y datos de R. Ray, J. Gornick y J. Schmitt, "Who cares? Assessing generosity and gender equality in parental leave policy designs in 21 countries", Journal of European Social Policy, vol. 20, $\mathrm{N}^{\circ}$ 3, Sage, 2010.

Nota: la duración de la licencia paternal se registró con relación a la unidad semanal de 7 días. En el caso del Uruguay, la licencia paternal se estimó a partir de una licencia maternal posnatal de 8 semanas (Ley 19.161, artículo 2). 
Con la excepción del Uruguay y la Argentina, en 2003 con las licencias maternales se reconocía el piso maternalista. El Uruguay se encontraba entonces dos semanas por debajo, y la Argentina - teniendo una licencia de 90 días - se hallaba poco más de una semana por debajo de las 14 semanas definidas por la OIT.

Durante este período, en Chile y el Uruguay las licencias se transformaron de manera considerable. Ya en 2003 Chile tenía la licencia maternal más extensa de los cinco países y la reforma de 2011 (Ley 20.545) le agregó tres meses. Dicha reforma también extendió la licencia por paternidad (de 3 a 5 días) y permitió a los padres usar hasta la mitad de los últimos tres meses de la licencia posnatal. Como resultado, la reforma promueve una combinación de acentuado maternalismo con un tímido avance en materia de corresponsabilidad paterna ${ }^{16}$.

En el Uruguay las licencias experimentaron varios cambios y en noviembre de 2013 tuvo lugar una reforma comprensiva para el sector privado (Ley 19.161). Un resultado de ello fue que en el sector privado la licencia por maternidad pasó de 12 a 14 semanas y a la licencia por paternidad de 3 días naturales en el sector privado y 10 hábiles en el público se agregaron 10 días naturales en el sector privado, tanto entre asalariados(as) como en autoempleados(as) que cotizan en el Banco de Previsión Socia $1{ }^{17}$. La extensión de la licencia por maternidad entró en vigencia de inmediato, mientras que las licencias por paternidad y parentales lo hacen gradualmente.

Desde la reforma legal introducida en 1989 mediante la Ley 16.109 , en el sector público la licencia por paternidad había sido de 3 días y a partir de 2008 de 10 días (Ley 17.930), cuando además se otorgaron 3 días a los trabajadores privados. La reforma de 2013 agrega a los 3 días naturales a cargo del empleador, 3 días más durante 2014, 7 días más en 2015 y 10 días más en 2016, todos estos financiados por el Banco de Previsión Social. Por lo tanto, los 13 días naturales de los privados pueden implicar una equiparación con los días hábiles del sector público (dependiendo de los días feriados que haya en medio de dicha licencia) ${ }^{18}$.

En 2016, la licencia parental permitirá a la madre o al padre trabajar media jornada una vez que haya finalizado la licencia maternal de 8 semanas posnatal

\footnotetext{
${ }^{16}$ Para un análisis del proceso de elaboración de la propuesta, véase Lupica (2013).

17 Quedan fuera personas autoempleadas formales que cotizan a la previsión social a través de las cajas profesionales.

18 Para una estimación de los costos de la reforma uruguaya, pero también metodológicamente útil con respecto a otros países, véase Salvador (2013).
}

y hasta que el hijo o la hija cumpla seis meses. Esta licencia de tiempo parcial durará un máximo de 4 meses o, para efectos de comparación, de 8 semanas a tiempo completo como se representa en el gráfico 1 (de acuerdo con Ray, Gornick y Schmitt, 2010).

Las reformas adoptadas en Chile y el Uruguay tienen distintas implicaciones para la equidad de género. En Chile, la licencia por maternidad se extendió por sobre el piso maternalista, mientras que en el Uruguay se la llevó al piso maternalista en el sector privado. La licencia por paternidad en el Uruguay dura al menos el doble que la adoptada en Chile, y en el Uruguay las licencias paternales son financiadas principalmente por la seguridad social y en menor medida por quien emplea al trabajador, mientras que en Chile y en el Brasil las financia quien contrata. En resumidas cuentas, la transformación uruguaya es en principio más favorable para la corresponsabilidad paterna que la chilena. En el otro extremo, la Argentina es el único de los cinco países que en 2014 aún no ha cumplido con el piso maternalista establecido por la OIT. Además, más allá de los casos de Chile y el Uruguay, a pesar de proyectos de ley que extienden las licencias por paternidad a entre 2 y 4 semanas en la Argentina, el Brasil y Costa Rica, las licencias paternales continúan siendo mínimas.

Dada la prominencia de las relaciones laborales informales, las licencias basadas en el empleo han sido particularmente desiguales desde una perspectiva socioeconómica. Puesto que la licencia por maternidad es por mucho la más substancial, en el gráfico 2 se aprecia el criterio de elegibilidad para acceder a ella en cada país en 2000 y 2013. Concretamente, el gráfico 2 permite observar la elegibilidad de solo algunas mujeres asalariadas, de todas las asalariadas o de todas las trabajadoras, incluidas las autoempleadas.

En 2003, en Chile y la Argentina solo una parte de las asalariadas accedían a las licencias por maternidad, excluyéndose precisamente a las trabajadoras socioeconómicamente más vulnerables. En Chile quedaban incluidas solo aquellas con contratos, sobre todo mujeres pertenecientes a los quintiles superiores de ingreso (Pribble 2006, pág. 90), aunque desde 1998 también tenían acceso las trabajadoras domésticas con contratos, que quedaban excluidas en la Argentina (donde representaban un $17 \%$ de la fuerza de trabajo urbana femenina). En el Brasil, Costa Rica y el Uruguay eran elegibles todas las asalariadas y en el caso brasileño se incluía a las trabajadoras independientes y temporales rurales. Incluso estas últimas no necesitaban probar sus aportes a la seguridad social para obtener una licencia de maternidad equivalente al salario mínimo. 
GRÁFICO 2
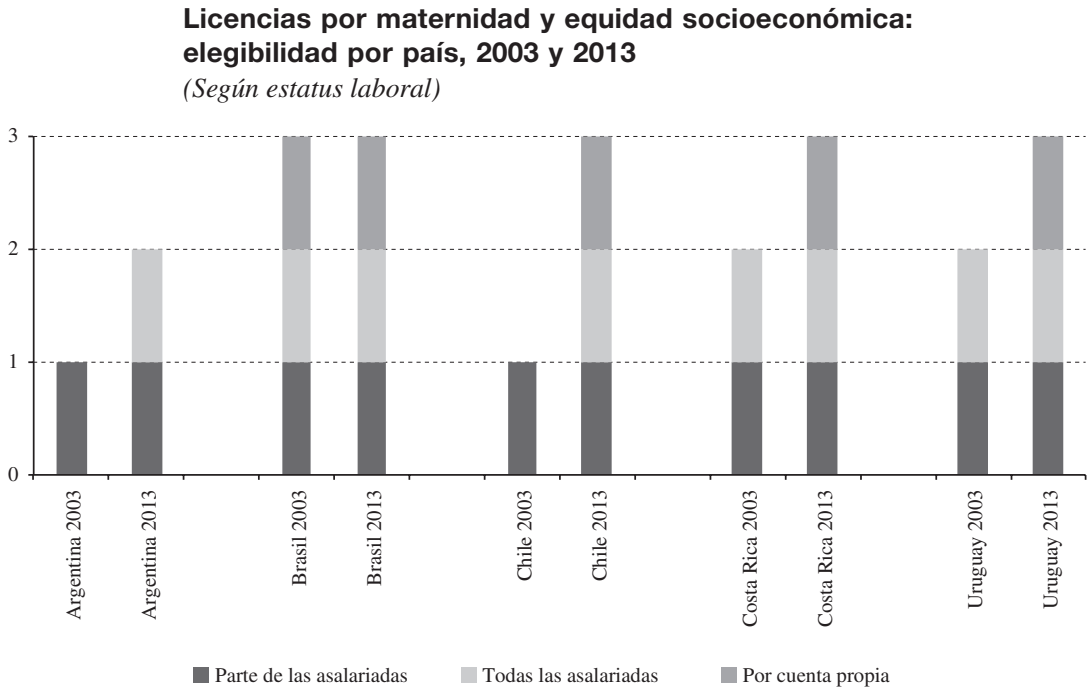

Fuente: elaboración propia sobre la base de la legislación de cada país.

Desde 2003, en los cinco países se han modificado las reglas de elegibilidad con vistas a una mayor equidad socioeconómica; en Costa Rica y el Brasil a través de la vía judicial y en los tres países restantes mediante cambios legislativos.

En la Argentina, una reforma legal adoptada en 2013 (y reglamentada en abril de 2014) amplió las licencias por maternidad a las trabajadoras domésticas, haciéndose así extensiva la elegibilidad a todas las asalariadas ${ }^{19}$. En el Brasil, un fallo del Tribunal Supremo de Trabajo en 2012 extendió el derecho a la licencia de maternidad a las trabajadoras temporales no agrícolas. En Chile, la reforma a la licencia parental en 2011 hizo extensiva la licencia por maternidad a todas las asalariadas, trabajadoras temporales e independientes. En Costa Rica, como parte de un acuerdo en materia de pensiones entre gobierno, cámaras, sindicatos y otras organizaciones, se estableció la obligatoriedad del aseguramiento del trabajo independiente ${ }^{20}$. Aunque inicialmente este solo incluyó a los servicios, en 2004 un fallo de la Corte Constitucional lo extendió a las transferencias monetarias $\mathrm{y}$, por consiguiente, a las licencias por maternidad. Las trabajadoras temporales se consideran asalariadas y su aseguramiento es, por lo tanto, obligatorio. Sin embargo, ha habido obstáculos para adecuar las condiciones de aseguramiento, por ejemplo, mediante contribuciones

\footnotetext{
${ }^{19}$ Ley 26.844 reglamentada mediante el decreto ejecutivo 467 de 2014.

${ }^{20}$ En 2008, la reforma de pensiones había reconocido y proporcionado una compensación del tiempo que las madres dedican a la crianza de sus hijos(as), aumentado la probabilidad de acceder a pensiones por vejez.
}

estacionales antes que mensuales. En el Uruguay, en 2013 el Poder Legislativo uruguayo hizo extensivas las licencias por maternidad a una parte de las trabajadoras aseguradas por cuenta propia ${ }^{21}$.

Las trabajadoras informales y que no realizan aportes a la seguridad social — generalmente, una proporción importante perteneciente a los quintiles de menores ingresos - quedan excluidas de estos criterios de elegibilidad, excepto las trabajadoras rurales en el Brasil ${ }^{22}$.

\section{Medidas desfamiliaristas: avances hacia la corresponsabilidad estatal con equidad socioeconómica en los servicios de cuidados}

A continuación se examinan las políticas adoptadas a nivel nacional respecto de servicios de cuidado y atención infantil, principalmente entre cero y tres años, y de manera complementaria entre cuatro y cinco años, respectivamente. Estos tramos corresponden a los grupos

\footnotetext{
${ }^{21}$ Como hizo ver Soledad Salvador (2014), se extienden en realidad todos los beneficios (paternidad y parentales) a hombres y mujeres que aportan al Banco de Previsión Social (no así a cajas independientes como las profesionales), y son titulares de empresas con hasta un dependiente, o titulares de empresas monotributistas. Si se trata de personas con algún dependiente, no figuran como por cuenta propia, sino como patrones.

22 Estas mujeres pueden ser elegibles para recibir otras transferencias en dinero en su condición de madres antes que de trabajadoras, principalmente mediante programas de transferencias monetarias condicionadas dirigidas a niños(as), a las propias madres embarazadas o a ambos.
} 
a los que se destinan los servicios de AEPI y a la educación prescolar, respectivamente. Dependiendo de cómo se define su jornada y de si alcanzan a la población de escasos ingresos, los servicios de cuidado promueven tanto corresponsabilidad estatal como equidad socioeconómica.

La educación preescolar tiende a reflejar preocupaciones estrictamente vinculadas a la formación de capital humano en mayor medida que los servicios de atención inicial. Por ello, los servicios orientados a la niñez entre cero y tres años permiten un mejor acercamiento al compromiso de los gobiernos con la conciliación entre vida familiar y laboral -es decir, la corresponsabilidad estatal— mediante servicios que desfamiliarizan parcialmente los cuidados y hacen prestaciones de tiempo completo. Es también en este tramo etario que existe una mayor reticencia social a que las madres combinen maternidad y trabajo remunerado y, en general, a la mera derivación de los cuidados en otras personas fuera del hogar.

En la Argentina, el Brasil y Chile, desde antes de 2003 existe legislación que mandata a las empresas grandes para que cuenten con ciertos servicios de atención infantil ${ }^{23}$. Estos se establecen en función del número de trabajadoras mujeres, están restringidos a las madres (no se habilitan a los padres) y fueron concebidos para permitir la lactancia durante el período legalmente establecido. En Chile, los empleadores con 20 o más trabajadoras deben disponer un servicio de guardería para niños(as) menores de dos años. En el Brasil, las compañías con 30 o más trabajadoras deben proveer servicio de guardería hasta los seis meses (por ende, durante un total de dos meses, entre la finalización de la licencia maternal obligatoria y la culminación del derecho a la lactancia a los seis meses). En la Argentina, desde 1970 los empleadores de 50 trabajadoras o más tienen la obligación legal de contar con servicio de guardería. Aunque la ley está vigente, su falta de reglamentación dificulta controlar su cumplimiento.

Durante el período considerado esta legislación no ha experimentado cambios. En la medida en que contar con algún servicio es mejor que no contar con ninguno, este marco legal es indicativo de algún grado de corresponsabilidad estatal, no así paterna. Sin embargo, el que sean servicios restringidos a un grupo pequeño del sector formal de madres trabajadoras los vuelve menos favorables a la equidad socioeconómica. Además, por

${ }^{23}$ La Ley 20.744 (1974); el artículo 389 del Código de Proceso del Trabajo, mediante el Decreto-Ley 229 de 1967; y el artículo 203 del Código del Trabajo, mediante la Ley 19.408 (1994), en la Argentina, el Brasil y Chile, respectivamente. tratarse de una medida maternalista, focalizada solo en las trabajadoras, puede desincentivar la contratación de mujeres en edad fértil o de un número mayor de mujeres por sobre el mínimo para el que la ley mandata servicios de guardería.

Los cambios que sí se observan en los servicios públicos han estado dirigidos a extender los servicios de AEPI. En seguida se analiza la existencia de servicios de tiempo completo en el marco de programas de nivel nacional dirigidos a la niñez entre 0 y 3 años de edad. En cada caso se determinan los criterios de elegibilidad (fundamentales para la equidad socioeconómica), y la existencia de metas y datos de cobertura. Estos dos últimos indicadores permiten valorar el grado de compromiso de los gobiernos con la corresponsabilidad estatal con los servicios de AEPI para niños(as) entre las edades de 0 a 3 años, y si promueven la equidad socioeconómica.

Excepto en la Argentina, en 2003 los países bajo estudio contaban con un programa nacional de atención y educación para la primera infancia entre 0 y 3 años. En el Brasil, Chile y el Uruguay estos programas - a los que luego se hará referencia con mayor detalle (centros de cuidado infantil, Junta Nacional de Jardines Infantiles (JUNJI), Fundación Integra y Centros de Atención Integral a la Primera Infancia (CAIF), respectivamente) — contaban con criterios explícitos de elegibilidad, no así en Costa Rica donde el acceso a los Centros de Educación y Nutrición/Centros Infantiles de Atención Integral (CEN/ CINAI) operaba según la necesidad económica, pero la aplicación de este criterio era relativamente discrecional y variable de acuerdo con la magnitud de la demanda a cada centro, volviéndose más focalizado ante una mayor demanda. Además, en el Brasil y el Uruguay se habían definido metas de cobertura, en el primer caso, muy ambiciosas. En términos socioeconómicos, los criterios de elegibilidad para acceder a los servicios de atención inicial oscilaban en un amplio rango: desde la carencia de un criterio estándar en Costa Rica a uno de corte universal en el Brasil a partir de la Constitución de 1988.

Hacia 2013, en la Argentina se había establecido un programa nacional - Centros de Desarrollo Infantil (CeDIs), sancionados mediante la Ley 26.233 en 2007-. En ese momento, en ninguno de los cinco países los programas restringían el acceso de niños y niñas según la situación laboral de las madres. Sin embargo, de distintas maneras, en varios de los programas se dio prioridad a niños(as) de madres trabajadoras a tiempo completo. Este es el caso del programa Chile Crece Contigo (ChCC) y de la expansión de la cobertura de 0 a 3 años en el Uruguay. Además, en los cinco países analizados, una 


\begin{tabular}{|c|c|c|c|}
\hline País & Programa & Criterio de elegibilidad & $\begin{array}{l}\text { Cobertura actual, meta y jornada } \\
\text { alrededor de } 2010^{\mathrm{b}}\end{array}$ \\
\hline \multirow[t]{2}{*}{ Argentina } & $\begin{array}{l}\text { Ley de Educación Nacional } \\
(2006)\end{array}$ & $\begin{array}{l}\text { Niños(as) a partir de los } 45 \text { días (se } \\
\text { reconocen servicios fuera del sector de la } \\
\text { educación formal) } \\
\text { Para } 0 \text { - } 3 \text { de edad no se expresa en acciones } \\
\text { específicas hasta la implementación de } \\
\text { ceDIs basado en criterio de necesidad }\end{array}$ & $\begin{array}{l}30 \% \text { en } 3 \text { años; } 67141 \text { niños(as) de } 0 \\
\text { a } 2 \text { años equivalentes a } 3,5 \% \text { de este } \\
\text { tramo etario }\end{array}$ \\
\hline & $\begin{array}{l}\text { Centros de Desarrollo } \\
\text { Infantil (ceDIs) (2007) }\end{array}$ & Necesidad económica & No existen datos; meta desconocida \\
\hline Brasil & $\begin{array}{l}\text { Ley de Directrices y Bases } \\
\text { de la Educación } \\
\text { (1996, financiamiento desde } \\
\text { 2007) }\end{array}$ & $\begin{array}{l}\text { Universal (en el marco del sistema } \\
\text { educativo) } \\
\text { Se expresa en la expansión de centros de } \\
\text { cuidado infantil (llamados "creches") }\end{array}$ & $\begin{array}{l}\text { En } 2010 \text { se cubría el } 18,4 \% \text { de niños con } \\
\text { promedio de } 8 \text { horas diarias (del } 50 \% \text { de } \\
\text { niños(as) de } 0 \text { a } 3 \text { años, definido como } \\
\text { meta en } 2001 \text { y ratificado en } 2010 \text { ) }\end{array}$ \\
\hline Chile & $\begin{array}{l}\text { Chile Crece Contigo } \\
\text { (chcc) }\end{array}$ & $\begin{array}{l}60 \% \text { más vulnerable de la población (en } \\
\text { el marco de servicios de cuidado fuera del } \\
\text { sistema educativo) } \\
\text { Se expresa en el programa chcc }\end{array}$ & $\begin{array}{l}\text { En } 2010 \text { se cubrían } 212000 \\
\text { cumpliendo la meta de crear } 113000 \\
\text { puestos adicionales }\end{array}$ \\
\hline Costa Rica & $\begin{array}{l}\text { Centros de Cuido y } \\
\text { Desarrollo Infantil } \\
(\text { CECUDI })(2010)\end{array}$ & $\begin{array}{l}\text { Necesidad con proyección universal (en el } \\
\text { marco de servicios de cuidado fuera del } \\
\text { sistema educativo) } \\
\text { Se expresa en expansión de los CECUDI a } \\
\text { partir de servicios nuevos y ya existentes }\end{array}$ & $\begin{array}{l}\text { Se pasó de cubrir } 7500 \text { a } 15000 \\
\text { niños(as) de } 0 \text { a } 6 \text { años, entre } 2010 \text { y } \\
2013 \text {; acorde con meta de aumento en } \\
8000 \text { niños(as) }\end{array}$ \\
\hline Uruguay & $\begin{array}{l}\text { Sistema Nacional de } \\
\text { Cuidados (2011) }\end{array}$ & $\begin{array}{l}\text { Necesidad con proyección universal (puede } \\
\text { ser fuera del sistema educativo) } \\
\text { Se expresa en expansión de los Centros de } \\
\text { Atención Integral a la Primera Infancia y la } \\
\text { Familia (CAIF) y de subsidios a la oferta }\end{array}$ & $\begin{array}{l}\text { En } 2009 \text { se cubría un } 13 \% \text { de } 0 \text { años, } \\
26 \% \text { de } 1 \text { año, } 29 \% \text { de } 2 \text { años y } 47 \% \text { de } \\
3 \text { años (un total de } 41216 \text { puestos en } \\
2008 \text { de la meta de } 43000 \text { para } 2009 \text { ) }\end{array}$ \\
\hline
\end{tabular}

Fuente: Argentina: Ana Malajovich, "La exclusión de los más vulnerables: Deudas educativas con la primera infancia”, Voces en el Fénix, $\mathrm{N}^{\circ}$ 3, Buenos Aires, Universidad de Buenos Aires, 2014; Lea Waldmann y otros, Servicios de atención a niños y niñas de 45 días a 36 meses, Buenos Aires, Fondo de las Naciones Unidas para la Infancia (UNICEF), 2011; Brasil: Plan Nacional de Educación 2001 y 2011-2020; PNAD/IBGE (2014); Costa Rica: Gobierno de Costa Rica, "Plan Nacional de Desarrollo 2010-2014”, María Teresa Obregón Zamora, San José, diciembre de 2010; Chile: Ministerio de Planificación/Ministerio de Salud (MIDEPLAN/MINSAL), Cuatro años creciendo juntos. Memoria de la Instalación del Sistema de Protección Integral a la Infancia Chile Crece Contigo 2006-2010, Santiago de Chile, 2010; Uruguay: Comité de Coordinación Estratégica de Infancia y Adolescencia (2010), "Estrategia Nacional para la Infancia y la Adolescencia (ENIA) $2010-2030$. Plan de Acción 2010-2015", Documento de Trabajo, Montevideo, 2010; Ana Cerutti y otros, Plan CAIF, 1988-2008, Montevideo, octubre de 2008; y Soledad Salvador, "Hacia un Sistema Nacional de Cuidados en Uruguay”, Montevideo, Comisión Económica para América Latina y el Caribe (CEPAL), 9 de diciembre de 2010.

a De 0 a 3 años.

b Cuando no se indica, se desconoce la proporción que corresponde a tiempo completo.

alta proporción de los servicios funcionan a tiempo parcial $^{24}$. Evidentemente, la contribución que desde estos servicios se hace a la corresponsabilidad estatal se ve condicionada por los horarios de operación de los centros, y resulta mayor cuando es más compatible con la jornada laboral formal y socialmente más protegida, como es la de tiempo completo.

24 Una valoración empírica de centros y usuarios bajo una u otra modalidad trasciende el ámbito del presente análisis.
Detallando la situación según países, en la Argentina, una reforma en la legislación educativa efectuada en 2006 definió los servicios a partir de los 3 años y la presencia de jardines de infantes para niños(as) de 45 días a 2 años (Ley 26.206). Sin embargo, estos servicios no llegaron a implementarse, como sí ocurrió con los Centros de Desarrollo Infantil (CeDIs) dirigidos a niños(as) de escasos recursos económicos y provistos tanto por el propio Estado como por organizaciones no gubernamentales (ONG) (Faur, 2011). 
En el Brasil, desde 1988 se había garantizado el derecho constitucional a la educación inicial desde 0 años y en 1996 este derecho se había convertido en ley. Sin embargo, es durante el período analizado que se avanzó en el cumplimiento del marco legal: en 2006 la responsabilidad de servicios de AEPI a nivel federal se trasladó desde el Ministerio de Desarrollo Social y Combate al Hambre al Ministerio de Educación, mientras que la implementación se mantuvo en los municipios. El principal reto ha sido desde entonces que los distintos niveles de gobierno hagan efectivo este derecho y, desde el punto de vista de la conciliación entre vida familiar y laboral, que él se exprese en jornadas de tiempo completo de los centros. La cobertura actual está lejos de garantizar esta prestación: en el año 2001, el Plan Nacional de Educación definió una meta de cobertura del $50 \%$ de la niñez entre 0 y 3 años para alcanzarla en 2010. Sin embargo, en 2010, y ante una cobertura de menos del $20 \%$, con el plan decenal se reiteró la meta del 50\% esta vez para 2020. El Estado tuvo un mejor desempeño en materia de la duración de las jornadas de atención de los centros de cuidado infantil (créches): en 2012 su jornada promedio era de ocho horas diarias, en comparación con menos de cinco horas al día de las escuelas preescolares (para niños y niñas de 4 y 5 años) (Ministerio de Educación (MEC)/Instituto Nacional de Estudios e Investigaciones Educacionales (INEP)).

A partir de 1994, Chile contaba con un programa relativamente acotado dirigido a las madres trabajadoras de menores ingresos. Bajo los servicios de JUNJI/ Integra, para calificar las madres trabajadoras debían contar con contratos formales y demostrar ingresos bajos (Pribble, 2006, pág. 91). En 2006, el gobierno de Michelle Bachelet creó el programa Chile Crece Contigo (ChCC) para coordinar y ampliar los servicios existentes para niños(as) en edad previa al preescolar, especialmente entre los quintiles de menores ingresos. En 2009, mediante la Ley 20.379 se institucionalizó "el derecho a una guardería y kínder de tiempo completo si las madres están trabajando, estudiando o buscando un empleo, y el derecho a una guardería de medio tiempo sin más requisitos relativos a las actividades de los padres" (Staab, 2012, pág. 313) para el 60\% económicamente más vulnerable de la población.

Entre 2006 y 2010, los cupos en salas cuna y jardines infantiles del chCC se duplicaron con creces, pasando de casi 97.000 a más de 210.000 (MIDEPLAN/MINSAL, 2010, págs. 59 y 60). Con el cambio de gobierno en 2010, la extensión de la cobertura se detuvo y dejaron de estar claras las metas de ampliación de cobertura.

En Costa Rica, el programa nacional de Centros de Educación y Nutrición/Centros Infantiles de Atención
Integral (CEN/CINAI) se formalizó durante los años setenta del siglo pasado y experimentó pocas transformaciones hasta 2010. Desde entonces, el gobierno de Laura Chinchilla creó la Red Nacional de Cuido y Desarrollo Infantil con carácter universal, que aglutinó a las modalidades de cuidado ya existentes (Sojo, 2011) y creó una nueva de carácter municipal, los Centros de Cuido y Desarrollo Infantil (CECUDI). Esta red se dirige a la niñez de 0 a 12 años con servicios universales, pero canalizando los subsidios públicos de manera focalizada (IMAS, 2013). Al año 2013 se contaba con criterios de elegibilidad explícitos, así como con metas de ampliación de cobertura -relativamente humildes, de inclusión de 8.000 niños(as) en servicios de tiempo completo (Gobierno de Costa Rica, 2010)— que incluían pero trascendían el tramo de 0 a 3 años de edad.

En el Uruguay, desde 1988 los Centros de Atención a la Infancia y la Familia (CAIF) brindaron servicios a la niñez de escasos recursos de 0 a 4 años (Pribble, 2006; Salvador, 2010, pág. 32). Las familias califican en función de su vulnerabilidad social y la edad de los niños (CAIF, 2008). En 2011, el gobierno de José Mujica anunció la creación de un Sistema Nacional Integrado de Cuidados dirigido a la niñez, la población adulta mayor y personas con discapacidad, el que luego de un buen avance en materia de definición de los principales componentes, se encuentra en una pausa en términos presupuestarios y de implementación. Bajo este sistema, el gobierno planea ampliar el criterio de elegibilidad para los servicios de AEPI, por lo pronto completando la cobertura a todos los niños del quintil inferior de ingreso. Mientras tanto, el quehacer de los CAIF se complementó con subsidios públicos con los que, desde el Ministerio de Desarrollo Social, se procura incorporar a niñas y niños en la oferta de jardines de infantes privados ya existentes.

La ampliación de servicios educativos de nivel preescolar público ha sido paralela a los cambios en materia de servicios de atención escolar de la primera infancia. Esta extensión, al igual que en el caso de la educación primaria, ha sido sobre todo de tiempo parcial. Las sucesivas ampliaciones del preescolar han tenido lugar tanto mediante un descenso en la edad de inicio, como de la definición de la edad a partir de la cual este acceso es obligatorio. Por esta vía, todos los países han dado pasos en la dirección de universalizar el acceso. Sin embargo, la ampliación de esta cobertura tuvo lugar en gran medida en escuelas de tiempo parcial $y$, por lo tanto, no ha extendido la corresponsabilidad en la conciliación entre vida familiar y laboral, a pesar de haberlo hecho en la corresponsabilidad en la educación preescolar per se. 
El preescolar en el Uruguay es un derecho a partir de los tres años desde 1995, pero inicialmente consagrado como obligatorio desde los 5 años y posteriormente desde los 4 (Pribble, 2013, pág. 89; Mancebo, 2012; Salvador, 2014). En Costa Rica se legisló la extensión gradual del preescolar universal de 5 a 4 años de edad en 1997, aunque manteniéndolo como obligatorio a partir de los 5 años. En la Argentina, desde 1993 la asistencia al prescolar era obligatoria desde los 5 años (Pautassi y Zibecchi, 2010, págs. 18 y 19). En 2006 se definió la extensión gradual pública y gratuita del prescolar a partir de los 4 años (Faur, 2008, págs. 56 y 57), aunque la obligatoriedad se mantuvo en los 5 años. En Chile, desde 2007 el preescolar universal comienza a los 4 años, aunque su obligatoriedad es a los 5 años de edad. En el Brasil el preescolar comienza a los 4 años de edad y en 2009 se estableció la obligatoriedad de la asistencia a los 4 años a partir de 2016.

\section{Medidas regulatorias: equiparación de derechos del trabajo doméstico remunerado}

En toda la región, el trabajo doméstico con remuneración constituye una estrategia familiar y femenina fundamental para la conciliación entre trabajo remunerado y responsabilidades familiares (CEPAL, 2013b). Por ello, tiene sentido considerar esta ocupación como aproximación a la manera en que los gobiernos regulan las ocupaciones vinculadas a los cuidados en general. Históricamente, la regulación social y laboral ha discriminado a estas trabajadoras de manera legal. Dado que en su mayoría se trata de mujeres en condiciones de vulnerabilidad socioeconómica, un tratamiento más equitativo de las trabajadoras domésticas remuneradas es indicador de mayores grados de equidad socioeconómica. A la vez, en tanto dos de los derechos en juego son los relativos a las jornadas laborales y a las licencias por maternidad, el análisis permite establecer avances en materia de corresponsabilidad estatal.

Interesa concretamente determinar en qué medida han tenido lugar reformas que equiparen sus derechos a los del resto de las personas ocupadas (Blofield, 2012). En el gráfico 3 se representan los derechos laborales de las trabajadoras domésticas garantizados en la legislación laboral nacional en 2003 y 2013. La comparación incluye protección social (seguridad social y licencias por maternidad) y regulación laboral (salario mínimo, vacaciones y una categoría referida a otras cláusulas discriminatorias). Un valor de seis denota que la legislación iguala derechos entre las trabajadoras domésticas y el resto de la población ocupada.

Como se muestra en el gráfico 3, en 2003 los códigos laborales de los cinco países discriminaban a las trabajadoras domésticas: su jornada diaria y semanal era más extensa que en las restantes ocupaciones. En el Uruguay en 2006, en Costa Rica en 2009 y en la Argentina y el Brasil en 2013 se igualaron estos derechos ${ }^{25}$. A mediados de 2014 - y aunque el Poder Ejecutivo cuenta con un proyecto de reforma-, únicamente en Chile se mantienen cláusulas discriminatorias.

La duración de la jornada laboral ha sido el derecho más difícil de equiparar legamente, lo que refleja una combinación de supuestos discriminatorios, tanto de género como socioeconómico. Por una parte, los oficios domésticos y los cuidados se conciben como una actividad que las mujeres realizan en su condición de mujeres. Al no ser considerado como un verdadero trabajo y, menos aún, un trabajo para el que se requiere calificación, a menudo se estima que su regulación puede prescindir de las normas y límites existentes para otras ocupaciones. Por otra, se entiende que las mujeres que desempeñan estas tareas deben estar incondicionalmente disponibles para atender a las familias de mayores recursos que las contratan. Las propias responsabilidades familiares de las trabajadoras domésticas se esfuman ante su condición de "servidoras" (Blofield, 2012).

En el gráfico 4 se compara la jornada legal semanal de las trabajadoras domésticas y del resto de la población económicamente activa (PEA) en los años 2003 y 2013. Las columnas presentan la diferencia en la duración de las jornadas semanales entre unas y otras ocupaciones. En 2003, la diferencia promedio superaba las 20 horas en todos los países ${ }^{26}$. En 2006 y en 2009, en el Uruguay y en Costa Rica, respectivamente, se equipararon las jornadas. En 2013, se hizo en la Argentina y el Brasil. En 2005, la brecha en la jornada semanal de las trabajadoras domésticas chilenas aumentó con respecto al resto de las trabajadoras, de 24 a 27 horas (con jornadas semanales de 72 horas en comparación con una reducción de 48 a 45 horas, respectivamente).

\footnotetext{
25 Estas últimas reformas ocurrieron luego de que en 2011 la oIT aprobara una convención en la materia.

${ }^{26}$ En el Brasil y el Uruguay no se explicitó la duración máxima de la jornada laboral. La regulación da a entender que descontando el tiempo para alimentación y descanso, estas trabajadoras deben de estar disponibles. Por ello el máximo se calcula en 16 horas diarias.
} 
GRÁFICO 3

Corresponsabilidad y equidad socioeconómica: cambios en los derechos laborales reconocidos a las trabajadoras domésticas en los códigos laborales por país, 2003 y 2013

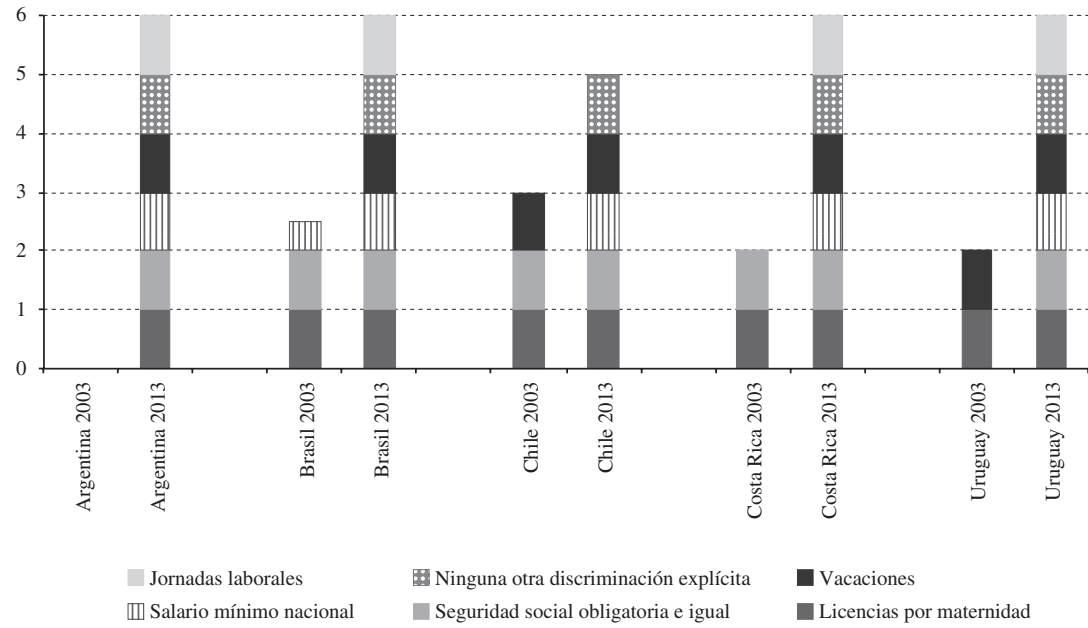

Fuente: elaboración propia, sobre la base de Merike Blofield, Care Work and Class: Domestic Workers' Struggle for Equal Rights in Latin America, University Park, Pensilvania, Penn State Press, 2012, y actualizado a 2013 sobre la base de las legislaciones nacionales de los respectivos países.

GRÁFICO 4

Diferencia en horas del máximo legal semanal entre trabajadoras domésticas y trabajadores(as) en general, 2003 y 2013

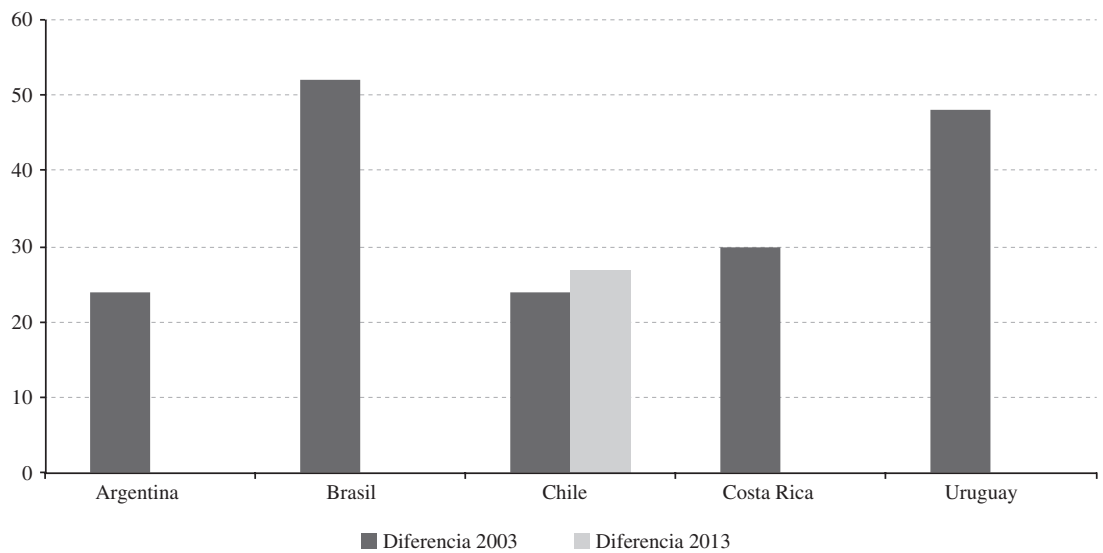

Fuente: elaboración propia, sobre la base de Merike Blofield, Care Work and Class: Domestic Workers' Struggle for Equal Rights in Latin America, University Park, Pensilvania, Penn State Press, 2012, y actualizado a 2013 sobre la base de las legislaciones nacionales de los respectivos países.

Desde la perspectiva de la conciliación entre vida familiar y laboral, una mayor garantía de los derechos laborales y sociales de las trabajadoras domésticas es indicativa de una mayor corresponsabilidad estatal en la compra de servicios, la que tiene efectos directos en materia de conciliación entre vida familiar y laboral por parte de las propias trabajadoras. El perfil socioeconómico de estas personas, principalmente mujeres, necesariamente vincula su condición socioeconómica y de género, por lo tanto, la manera cómo el Estado aborda sus condiciones 
laborales es una medida del valor que este le otorga a ambos tipos de equidad. Así, cualquier medida que mejore sus condiciones, fomenta ambas dimensiones de la equidad.

En el corto plazo, la garantía de derechos y, en consecuencia, el encarecimiento de esta forma de conciliación para las familias que contratan este trabajo aún marcadamente informal, puede agravar las tensiones entre vida laboral y familiar. A la vez, en el mediano y largo plazo la formalización laboral de estas trabajadoras puede potencialmente incentivar acciones colectivas en torno de medidas secuenciales y desfamiliaristas de carácter institucional.

\section{V}

\section{Análisis y conclusiones}

Durante los últimos 10 años, en América Latina se ha logrado revertir ligeramente las desigualdades socioeconómicas. Sin embargo, a fines de la década de 2000, la brecha entre la participación laboral de las mujeres pobres y no pobres era similar a la brecha existente a inicios de la década. Dado que las desigualdades socioeconómicas y de género están estrechamente vinculadas, abordar el nexo trabajo-familia desde la política pública es una condición necesaria para reducir cualquier tipo de desigualdad. Asimismo, no cualquier tipo de política promueve simultáneamente equidad socioeconómica y de género. Para analizar si ha habido avances y de qué tipo, en este artículo se discutieron los cambios en materia de licencias basadas en el empleo, de servicios de cuidado y de protección laboral de las trabajadoras domésticas como indicadoras de políticas secuenciales, desfamiliaristas y regulatorias, respectivamente. Sobre la base de una reelaboración de estos tipos de políticas conciliatorias, la principal contribución de este artículo es presentar un instrumento que, de manera sencilla y comparada, permite establecer cuántos y qué tipo de cambios han ocurrido, en este caso, entre 2003 y 2013 en los cincos países considerados, y con qué implicaciones — desde el diseño antes que de la implementación de política - para la desigualdad.

La evidencia relativa a la adopción de medidas nos dice que los grados de cambio variaron a través de los países y de los tipos de política. En la comparación nacional, en 2003 la Argentina y Chile contaban con políticas conciliatorias comparativamente menos incluyentes. Hacia 2013, sin embargo, en Chile y particularmente en el Uruguay se habían introducido reformas en los tres tipos de políticas considerados, mientras que la Argentina, en términos de las políticas examinadas y siempre en contrapunto con los restantes países, permanecía rezagada. Tanto en 2003 como en 2013, el Brasil y Costa Rica tenían un desempeño variable entre políticas.
El análisis comparativo permite, además, conocer el tipo de transformación promovido. En los cinco países las medidas adoptadas han procurado extender las licencias maternales a los grupos más vulnerables de trabajadoras, ampliar la expectativa de servicios de cuidado en la primera infancia como un derecho propio de niños y niñas, y regular el trabajo doméstico remunerado. Se trata pues de medidas extremadamente relevantes para las mujeres de menores ingresos y, por lo tanto, positivas desde el punto de vista de que la política pública promueva una mayor equidad socioeconómica.

Comenzando por el trabajo doméstico, su mayor protección indica una mayor corresponsabilidad estatal en la conciliación entre vida familiar y laboral mediante su intervención en las condiciones de mercantilización de los cuidados que tienen lugar de manera remunerada en los hogares. A la vez, en el largo plazo, respecto de las familias que contratan este trabajo, estas medidas podrían crear condiciones para que desde el Estado se diseñen mejores medidas secuenciales y desfamiliaristas.

En materia de servicios de cuidado de la primera infancia, cuando promueven la jornada completa, estos servicios han extendido la corresponsabilidad estatal en la conciliación entre vida familiar y laboral. Es destacable que, en los cinco países, la obligación de los empleadores de brindar servicios de cuidado se mantenga sin cambios.

Finalmente, las reformas de las licencias basadas en el empleo han sido heterogéneas. En todos los países los gobiernos han adoptado medidas favorables a una mayor equidad socioeconómica. En dos países, Chile y el Uruguay, se han dado pasos hacia la corresponsabilidad paterna mediante la extensión de las licencias paternales (que aunque siguen siendo mínimas, son el doble de largas en el Uruguay con respecto a Chile) y la creación de las licencias parentales (con distintas modalidades en ambos países). Al mismo tiempo, la reforma chilena es comparativamente maternalista, en tanto que la licencia 
por maternidad extendida refuerza la noción de que el cuidado de niños(as) es sobre todo una responsabilidad materna. En los restantes tres países las licencias paternales han estado en la agenda, pero no han sido adoptadas.

En las medidas tendientes a asegurar un piso maternalista más allá de las licencias, se incluyen el crédito por cada niño(a) establecido en Chile y el aporte a las pensiones por cada niño o niña que nace vivo en el Uruguay, que en la medida que reconocen el papel diferenciado de las mujeres, procuran nivelar sus condiciones socioeconómicas con las de sus pares varones.

El análisis efectuado en este trabajo indica que, como regla general, las políticas continúan considerando el cuidado de niños(as) pequeños(as) como una responsabilidad de las madres. En general, tanto por medio de medidas secuenciales - como son las licencias-, como desfamiliaristas y de regulación de las ocupaciones del cuidado, el avance es mayor en cuanto a promover la equidad socioeconómica que en promover la corresponsabilidad paterna, si bien las reformas recientes en Chile y el Uruguay indican un cambio pequeño pero cualitativo en esa dirección. Aunque en la mayoría de los países se tematiza de manera creciente la importancia de contar con servicios de atención infantil de jornada completa, el desempeño en materia de corresponsabilidad estatal es aún difícil de establecer.

El análisis, enfocado en caracterizar cambios y continuidades con una perspectiva comparada, deja planteadas tres tipos de preguntas, relacionadas - primero- con la efectividad en la implementación de las medidas adoptadas; segundo, con la capacidad que estas medidas tengan en el mediano y largo plazo para alterar la desigualdad inicial en materia de cuidados y de conciliación entre vida familiar y laboral; y tercero, con los determinantes sociales y políticos que dan cuentan de las variaciones entre países y políticas.

\section{Bibliografía}

Aguirre, Rosario y Fernanda Ferrari (2014), "La construcción del sistema de cuidados en el Uruguay: En busca de consensos para una protección social más igualitaria”, Serie Políticas Sociales, $\mathrm{N}^{\circ} 192$ (LC/L.3805), Santiago de Chile, Comisión Económica para América Latina y el Caribe (CEPAL).

Batthyany, Karina, Natalia Genta y Valentina Perrotta (2012), "La población uruguaya y el cuidado: Persistencias de un mandato de género. Encuesta nacional sobre representaciones sociales del cuidado: Principales resultados", Serie Mujer y Desarrollo, № 117 (LC/L.3530), Santiago de Chile, Comisión Económica para América Latina y el Caribe (CEPAL).

Bentancor, Andrea y María Isabel de Martini (2012), Detrás de la puerta: Trabajo, roles de género y cuidado, Santiago de Chile, Comunidad Mujer.

Blofield, Merike (2012), Care Work and Class: Domestic Workers' Struggle for Equal Rights in Latin America, University Park, Pensilvania, Penn State Press.

Blofield, Merike y Juliana Martínez Franzoni (2014), "Maternalism, co-responsibility and social equity: a typology of work-family policies", Social Politics, junio.

CAIF (Centros de Atención Integral a la Primera Infancia y la Familia) (2008), El Plan CAIF, Montevideo, Secretaría Ejecutiva Plan CAIF.

CEPAL (Comisión Económica para América Latina y el Caribe) (2013a), Panorama Social de América Latina, 2013 (LC/G.2580), Santiago de Chile. Publicación de las Naciones Unidas, $\mathrm{N}^{\circ}$ de venta: S.14.II.G.6.

(2013b), Panorama Social de América Latina, 2012 (LC/G.2557-P), Santiago de Chile. Publicación de las Naciones Unidas, $\mathrm{N}^{\circ}$ de venta: S.13.II.G.6.

(2011), "Cuidado infantil y licencias parentales", Desafios: Boletín de la Infancia y Adolescencia sobre el Avance de los Objetivos de Desarrollo del Milenio, $\mathrm{N}^{\circ} 12$, Santiago de Chile, Comisión Económica para América Latina y el Caribe (CEPAL)/Fondo de las Naciones Unidas para la Infancia (UNICEF), julio.

(2010), Panorama Social de América Latina, 2009 (LC/ G.2423-P), Santiago de Chile. Publicación de las Naciones Unidas, $\mathrm{N}^{\circ}$ de venta: S.09.II.G.135.
Cerutti, Ana y otros (2008), Plan CAIF, 1988-2008, Montevideo, octubre.

Chioda, Laura (2011), Work and Family: Latin America \& Caribbean Women in Search of New Balance, Washington, D.C., Banco Mundial.

Comité de Coordinación Estratégica de Infancia y Adolescencia (2010), "Estrategia Nacional para la Infancia y la Adolescencia (ENIA) 2010-2030. Plan de Acción 2010-2015”, Documento de Trabajo, Montevideo.

Cornia, Giovanni (2010), "Income distribution under Latin America's new left regimes", Journal of Human Development and Capabilities, vol. 11, $\mathrm{N}^{\circ} 1$, Taylor \& Francis, febrero.

Durán, María-Ángeles (2004), “Cómo conciliar trabajo y vida familiar? Un desafío colosal" [en línea] http://www.comfia. info/index.php?modo=leer\&art=14814.

England, Paula y Nancy Folbre (1999), "The cost of caring", The Annals of the American Academy of Political and Social Science, vol. 561, $\mathrm{N}^{\circ}$ 1, American Academy of Political and Social Science.

Esping-Andersen, Gøsta (2009), The Incomplete Revolution: Adapting to Women's New Roles, Cambridge, The Polity Press. (1990), The Three Worlds of Welfare Capitalism, Cambridge, Polity Press.

Faur, Eleonor (2011), "A widening gap? The political and social organization of childcare in Argentina", Development and Change, vol. 42, $\mathrm{N}^{\circ} 4$, Wiley.

(2008), The "Care Diamond": Social Policy Regime, Care Policies and Programmes in Argentina, Ginebra, Instituto de Investigaciones de las Naciones Unidas para el Desarrollo Social (UNRISD).

Faur, Eleonor, Valeria Esquivel y Elizabeth Jelin (eds.) (2012), Las lógicas del cuidado infantil: Entre las familias, el Estado y el mercado, Buenos Aires, Instituto de Desarrollo Económico y Social (IDES).

Filgueira, Fernando (2011), "Fault lines in Latin American social development and welfare regime challenges", The Great Gap: Inequality and the Politics of Redistribution in Latin America, Merike Blofield (ed.), College Park, Pensilvania, Pennsylvania State University Press. 
Folbre, Nancy (1995), "Holding hands at midnight: the paradox of caring labor", Feminist Economics, vol. 1, $\mathrm{N}^{\circ}$ 1, Taylor \& Francis, febrero.

Fraser, Nancy (1997), Justice Interruptus: Critical Reflections on the "Postsocialist" Condition, Londres, Routledge.

Gherardi, Natalia, Laura Pautassi y Carla Zibecchi (2012), De eso no se habla: El cuidado en la agenda pública. Estudio de opinión sobre la organización del cuidado, Buenos Aires, Equipo Latinoamericano de Justicia y Género (ELA).

Gobierno de Chile (2009), "Sistema de protección a la infancia: Chile Crece Contigo", Santiago de Chile.

Gobierno de Costa Rica (2010), "Plan Nacional de Desarrollo 20102014", María Teresa Obregón Zamora, San José, diciembre.

Goldin, Claudia (2006), "The quiet revolution that transformed women's employment, education, and family", American Economic Review, vol. 96, Nㅜㄹ 2, Nashville, Tennessee, American Economic Association, enero.

Hirata, Helena y Nadya Araujo Guimarães (eds.) (2012), Cuidado e cuidadoras: As várias faces do trabalho do care, São Paulo, Editora Atlas.

Huber, Evelyne y John Stephens (2012), Democracy and the Left: Social Policy and Inequality in Latin America, Chicago, The Chicago University Press.

IMAS (Instituto Mixto de Ayuda Social) (2013), Monto de los subsidios para la participación en las diferentes alternativas de cuido y desarrollo infantil y directrices técnicas de cooperación, SEPS-022-1-13, San José, enero.

Koven, Seth y Sonya Michel (1993), Mothers of a New World: Maternalist Politics and the Origins of Welfare States, Nueva York, Routledge.

López-Calva, Luis y Nora Lustig (2010), Declining Inequality in Latin America: a Decade of Progress?, Washington, D.C., Brookings Institution.

Lupica, Carina (2013), Trabajo decente y cuidado compartido: Hacia una propuesta de parentalidad, Santiago de Chile, Organización Internacional del Trabajo (OIT)/Programa de las Naciones Unidas para el Desarrollo (PNUD).

Malajovich, Ana (2014), "La exclusión de los más vulnerables: Deudas educativas con la primera infancia", Voces en el Fénix, $\mathrm{N}^{\circ} 3$, Buenos Aires, Universidad de Buenos Aires.

Mancebo, Esther (2012), Personal communication, 13 de julio.

Martínez Franzoni, Juliana y Rosalía Camacho (2007), "Equilibristas o malabaristas..., pero ¿con red? La actual infraestructura de cuidados en América Latina", Entre familia y trabajo: Relaciones, conflictos y políticas de género en Europa y América Latina, María Antonieta Carbonero y Silvia Levín (eds.), Rosario, Homo Sapiens Ediciones.

(2006), "Género, políticas conciliatorias y presupuesto público: Una aproximación al caso de América Latina y el Caribe", Cohesión social, políticas conciliatorias y presupuesto público. Una mirada desde el género, Luis Mora, María José Moreno y Tania Rohrer (coords.), México, D.F, Fondo de Población de las Naciones Unidas (UNFPA)/Agencia Alemana de Cooperación Técnica (GTZ).

Martínez Franzoni, Juliana (2008), "Welfare regimes in Latin America: Capturing constellations of markets, families and policies", Latin American Politics and Society, vol. 50, $\mathrm{N}^{\circ} 2$, Wiley, junio.

Martínez Franzoni, Juliana y Diego Sánchez-Ancochea (2013), "Public social goods and income inequality", A Primer on Labour Market Institutions and Inequality, Ginebra, Organización Internacional del Trabajo (OIT), en prensa.

MidePlan/Minsal (Ministerio de Planificación/Ministerio de Salud) (2010), Cuatro años creciendo juntos. Memoria de la Instalación del Sistema de Protección Integral a la Infancia Chile Crece Contigo 2006-2010, Santiago de Chile.
Ministerio de Desarrollo Social (2011), Plan Nacional de Acción por los Derechos de Niños, Niñas y Adolescentes 2012-2015, Buenos Aires.

Ministerio de Educación (2011), "Plano Nacional da Educaçao 2011-2020", Brasilia.

(2001), "Plano Nacional da Educaçao 2001", Brasilia.

Monge, Guillermo (2006), "Igualdad de género, pobreza y políticas de conciliación entre los ámbitos productivo y reproductivo y presupuestos públicos", México, D.F.

Montaño Virreira, Sonia (2010), "El cuidado en acción", El cuidado en acción: Entre el derecho y el trabajo, serie Cuadernos de la CEPAL, No 94 (LC/G.2454-P), Sonia Montaño y Coral Calderón Magaña (eds.), Santiago de Chile, Comisión Económica para América Latina y el Caribe (CEPAL). Publicación de las Naciones Unidas, $\mathrm{N}^{\circ}$ de venta: S.10.II.G.35.

ort (Organización Internacional del Trabajo) (2012), Panorama Laboral 2012. América Latina y el Caribe, Lima, Oficina Regional de la oIT para América Latina y el Caribe.

(2011), Panorama Laboral 2010. América Latina y el Caribe, Lima, Oficina Regional de la orT para América Latina y el Caribe.

OIT/PNUD (Organización Internacional del Trabajo/Programa de las Naciones Unidas para el Desarrollo) (2009), Trabajo y familia: Hacia nuevas formas de conciliación con corresponsibilidad social, Santiago de Chile.

Orloff, Ann Shola (2009), "Gendering the comparative analysis of welfare states: an unfinished agenda", Sociological Theory, vol. $27, \mathrm{~N}^{\circ} 3$, Wiley, septiembre.

(2006), "Farewell to maternalism? State policies and mothers' employment", The State After Statism, Jonah Levy (ed.), Cambridge, Massachusetts, Harvard University Press.

Pautassi, Laura y Carla Zibecchi (2010), "La provisión de cuidado y la superación de la pobreza infantil. Programas de transferencias condicionadas en Argentina y el papel de las organizaciones sociales y comunitarias", Serie Políticas Sociales, $\mathrm{N}^{\circ} 159$ (LC/L.3198-P), Santiago de Chile, Comisión Económica para América Latina y el Caribe (CEPAL). Publicación de las Naciones Unidas, $\mathrm{N}^{\circ}$ de venta: S.10.II.G.10.

Pautassi, Laura y Nieves Rico (2011), "Cuidado infantil y licencias parentales", Desafíos: Boletín de la infancia y adolescencia sobre el avance de los Objetivos de Desarrollo del Milenio, $\mathrm{N}^{\circ} 12$ (ISSN 1816-7535), Santiago de Chile: Comisión Económica para América Latina y el Caribe (CEPAL) y Fondo de las Naciones Unidas para la Infancia (UNICEF), abril.

PNAD/IBGE (2014), "Encuesta Nacional de Hogares/Instituto Brasileño de Geografía y Estadística" [en línea] http://www. ibge.gov.br/home/estatistica/indicadores/trabalhoerendimento/ pnad_continua/default.shtm.

Presidencia de la República Federativa de Brasil (2009), "Emenda constitucional 59", 11 de noviembre.

Pribble, Jennifer (2013), Between Elites and the Masses: Political Parties and Welfare Regimes in Latin America, Cambridge, Cambridge University Press.

(2006), "The politics of women's welfare in Chile and Uruguay", Latin American Research Review, vol. 41, № 2, Asociación de Estudios Latinoamericanos (LASA), diciembre.

Ray, Rebecca, Janet Gornick y John Schmitt (2010), "Who cares? Assessing generosity and gender equality in parental leave policy designs in 21 countries", Journal of European Social Policy, vol. 20, $\mathrm{N}^{\circ} 3$, Sage.

Rodríguez, Corina y Laura Pautassi (coords.) (2014), La organización social del cuidado de niños y niñas: Elementos para la construcción de una agenda de cuidados en Argentina, Buenos Aires, Asociación por los Derechos Civiles (ADC)/Centro Interdisciplinario para el Estudio de Políticas Públicas (CIEPP)/ Equipo Latinoamericano de Justicia y Género (ELA). 
Román, Isabel y Natalia Morales (2010), "Demanda potencial de cuido infantil según estructura de los hogares: El caso de Costa Rica", Convenio entre el INAMU y el Programa Estado de la Nación, San José.

Salvador, Soledad (2014), "Comunicación personal", Montevideo, 4 de abril.

(2013), "Análisis de costos y posibles impactos de diferentes modelos de licencias por maternidad, paternidad y parentales. Informe final de consultoría en el marco del proyecto URY2U503", Documento de Trabajo, 15 de febrero. (2010), "Hacia un Sistema Nacional de Cuidados en Uruguay", Montevideo, Comisión Económica para América Latina y el Caribe (CEPAL), 9 de diciembre.

Sauma, Pablo (2012), "Protección social y trabajo no remunerado: Redistribución de las responsabilidades y tareas del cuidado. Estudio de caso Costa Rica", Serie Mujer y Desarrollo, $\mathrm{N}^{\circ} 116$ (LC/L.3519), Santiago de Chile, Comisión Económica para América Latina y el Caribe (CEPAL).

Sojo, Ana (2011), "De la evanescencia a la mira: El cuidado como eje de políticas y de actores en América Latina", Serie Seminarios y Conferencias, $\mathrm{N}^{\circ} 67$ (LC/L.3393), Santiago de Chile, Comisión Económica para América Latina y el Caribe (CEPAL).

Sorj, Bila (2013), "Arenas de cuidado nas interseções entre género e classe social no Brasil", Cadernos de Pesquisa, vol. 43, $\mathrm{N}^{\circ} 149$, Sao Paulo, mayo-agosto.

Sorj, Bila y Adriana Fontes (2012), "O care como um regime estratificado: Implicações de género e classe social", Cuidado e cuidadoras. As várias faces do trabalho do care, Helena Hirata y Nadya Araujo Guimaraes (orgs.), São Paulo, Atlas.

Staab, Silke (2012), "Maternalism, male-breadwinner bias and market reform: historical legacies and current reforms in Chilean social policy", Social Politics, vol. 19, N 3 .

Waldmann, Lea y otros (2011), Servicios de atención a niños y niñas de 45 días a 36 meses, Buenos Aires, Fondo de las Naciones Unidas para la Infancia (UNICEF).

Williams, Fiona (2010), "Claiming and framing in the making of care policies: the recognition and redistribution of care", Gender and Development Programme, $\mathrm{N}^{\circ} 13$, Ginebra, Instituto de Investigaciones de las Naciones Unidas para el Desarrollo Social (UNRISD), noviembre. 